\title{
Y si sólo tu indiferencia hemos de merecer... Los lectores, el gros public y la Revista Moderna
}

Yliana Rodríguez González

Instituto de Investigaciones Filológicas - Universidad Nacional Autónoma de México, México

\begin{abstract}
Resumen
En este artículo me propongo explorar las posibilidades de lectura y la índole de los lectores que encuentro en Revista Moderna (RM), en su primera época (1898-1903), a partir de tres nociones fundamentales: la petite revue, como fenómeno mediático de fin de siglo que la define en formato y circulación; el "nosotros", que alude a una colectividad, reivindicada y asumida por el impreso y que suma lo mismo a redactores que a lectores y, por último, la endogamia literaria como práctica escritural-lectora que se verifica en la Revista. Los indicios materiales y algunas noticias a propósito de la primera recepción son tomados en cuenta para alcanzar conclusiones al respecto.
\end{abstract}

\section{If only your indifference we could merit.. Readers, the gros public and Revista Moderna}

\begin{abstract}
My aim in this article is to explore the reading practices and the nature of the readers that I find in Revista Moderna ( $R M)$, in its first period (1898-1903), based on three fundamental notions: the petite revue, as a media phenomenon of the end of the century that helps to define Revista Moderna in ist format and circulation; the concept of "we", which refers to a collectivity, vindicated and assumed by the journal, and that combines editors and readers, and, finally, literary inbreeding as a scripture/reading practice that develops in the journal. The material data and some information regarding to the first reception are taken into account to reach conclusions in this regard.
\end{abstract}

\section{Resumo}

Neste trabalho eu me proponho explorar as possibilidades de leitura e a natureza dos leitores que encontro na Revista Moderna ( $R M)$, em seu primeiro período (1898-1903), baseado em três noções fundamentais: a petite revue, como um fenômeno midiático
Palabras clave lectores Revista Moderna petite revue endogamia literaria materialidad

Keywords

readers Revista Moderna petite revue literary inbreeding material data
Palavras-chave

Leitores

Revista Moderna petite revue

"endogamia" literaria sinais materiais 
do final do século, que define seu formato e seu circulação; o "nós", que se refere a uma coletividade, reivindicada e assumida pela forma impressa, e que suma editores e leitores e, finalmente, la "endogamia" literária como prática de leitura e escrita que é verificada na revista. Os sinais materiais e la primeira recepção são levados em conta para chegar a conclusões sobre o assunto.

A propósito de los lectores de Revista Moderna $(R M),{ }^{1}$ los especialistas están de acuerdo en señalar que la pérdida del archivo del impreso entorpece la posibilidad de obtener datos duros a propósito de su recepción, suscriptores y tiraje (Pineda Franco, 2006a: 156). Adela Pineda Franco, por ejemplo, ha decidido acudir a fuentes secundarias, así como a evidencias materiales aportadas por la propia revista, para alcanzar algunas conclusiones al respecto. Por su parte, Elisa Speckman señala, junto a María Esther Pérez Salas, Fausto Ramírez y Carlos Monsiváis, que, si bien la revista era leída por un número reducido de enterados y conocedores de las innovaciones en letras y artes (2005: 68), también es verdad que el gesto de autoencomio y automarginación (Pineda Franco, 2006a: 157) que la caracterizó revela que muchos de sus lectores estaban, sobre todo, entre los propios literatos. A ellos, Pineda Franco suma a "los consumidores prototípicos del materialismo y la urbanización", una élite - notablemente masculina - interesada en la novedad, sea cual fuera su índole (2005: 255) y, en otro momento, a las mujeres, para su segunda época (Pineda Franco, 2006b: 113-117). Respecto de la materialidad, que ofrece noticias relativas a los lectores, sabemos que el ejemplar costaba cincuenta centavos, aunque el "número suelto con compromiso de tomar un trimestre cuando menos" era de doce centavos (frente a los veinte que costaba, por ejemplo, El Mundo Ilustrado), y que la suscripción anual era de \$6.50; que privilegiaba cierta índole de imágenes (con las del pintor Julio Ruelas como su divisa) y que ofrecía un formato singular, equilibrado, atento a la legibilidad. El diseño de su parcelación parece excluir a ciertos lectores y atender/formar a los posibles abonados, lo que se reitera en una armonía composicional aparentemente más cercana a la página de un libro que a la de un diario, aunque, y esto me importa subrayarlo, para el momento de aparición de $R M$, la revista como objeto había dejado de ser esa publicación híbrida, justamente a medio camino entre el libro y el periódico, para constituirse en un ente aparte, independiente y reconocible en el mundo de los impresos (Loué, 2011:357): una nueva institución en el mundo literario (Vérilhac, 2011: 373), que pretende desempeñar un papel eficaz en la organización de la literatura (368).

La configuración del objeto revista de fin de siglo representa, además, y se origina en, un momento de crisis de la prensa periódica, no solo en lo relativo a sus contenidos y formatos, sino también a propósito de los lectores; ${ }^{2}$ los rasgos que la definen permiten suponer que sus lectores fueron, en efecto, los abonados habituales de este tipo de objetos, fundamentalmente en la primera época, porque sostengo que la variedad y la concesión/amplitud en la oferta de parte de la revista se anuncia en la primera, pero llega en la segunda época. $R M$ es una petite revue, esto quiere decir, prensa parainstitucional que, por su naturaleza novedosa de edición y difusión, de promoción y activismo (Vérilhac, 2011:361;368), contaba con datos de tiraje variable (generalmente ocultos) y una fragilidad económica que descansaba en un sistema de suscripciones y abonos y/o una suerte de mecenazgo de parte de un miembro acaudalado del propio grupo o de un impresor (Vérilhac, 2011:361-363), ${ }^{3}$ condiciones que afectan su lectura.

En este artículo me propongo explorar las posibilidades de lectura y la índole de los lectores de $R M$, en su primera época (1898-1903), a partir de tres nociones fundamentales: la petite revue, como fenómeno mediático de fin de siglo, que define formato y 
circulación; el "nosotros", que alude a una colectividad, reivindicada y asumida por el impreso y que suma lo mismo a redactores que a lectores, y, por último, la endogamia literaria como práctica escritural-lectora verificada en el impreso.

\section{Del gros public a la petite revue}

Cuando se habla de los autores modernistas de finales del siglo XIX en México, generalmente se alude a la falta de público que tuvieron sus obras, aunque bien mirado, y como afirma José Emilio Pacheco, el fenómeno tenía sus raíces más en un menosprecio colectivo hacia la literatura en general, que en una exclusiva hostilidad al Modernismo (Pacheco, 1999: xlv). Los escritores realistas habían expresado desencanto ante la falta de lectores y demanda de libros, de papel barato, de editores progresistas, de estímulo, de compañerismo y de prensa culta, y su impotencia ante las horas entregadas al periodismo voraz (De Campo, 1991: 128). Si bien es posible afirmar que este lamento se configuró en un lugar común para los escritores del siglo XIX prácticamente en cualquier latitud, lo cierto es que la segunda generación modernista, autora del proyecto de $R M$, lo compartió, pero se apropió de él con otro talante; al contrario que los escritores realistas, adoptó una postura desafiante, provocativa y desdeñosa frente a la sociedad que la ignoraba: no tener lectores empieza a constituir un indicio positivo, legitimador del escritor y de su obra. Amado Nervo, por ejemplo, sostenía, en un texto publicado en 1896 , lo que se puede considerar como la actitud modernista ante los posibles lectores: "de nada sirve escribir para el pueblo, ya que el pueblo no comprende sino canciones del género vulgar. Los que para el pueblo han escrito no han sido comprendidos por él" (Nervo, 1896: 187).

La idea del lector de $R M$ aparece esbozada muy temprano, antes que la propia revista, en la carta que José Juan Tablada dirige a Balbino Dávalos, Jesús Urueta, José Peón del Valle, Alberto Leduc y Francisco Olaguíbel tras el affaire de "Misa negra". ${ }^{4}$ Allí, José Juan Tablada insiste en que al público le causa indignaciones y furores el ideal que a su grupo le entusiasma. Y enfatiza: "desde hoy nuestras obras literarias quedan excluidas de los periódicos que tienen por principal objeto mediar en el ánimo público" (Tablada,1893: xxi). Esto quiere decir que su ideal ha sido arrojado del paraíso burgués, aunque paradójicamente sea allí donde encuentre a sus posibles lectores. Tanto el término "moderno" (constitutivo más tarde del título de su órgano difusor) como su derivado, "modernismo" (que, por cierto, asomará pocas veces en él), apelan a dos nociones vinculadas con los dichos de Tablada: hacer de lo nuevo el máximo valor, por un lado, y por el otro, romper con la modernidad burguesa (Goldgel, 2013: 37). Esa ruptura surge de un afán de profesionalismo, que busca espacios, legitimación y público, como sostiene Julio Ramos:

De modo que la posición "profesionalista" responde a un doble frente de lucha: por un lado, se distancia del escritor estrictamente mercantil del periódico, pero a la vez reconoce en el mercado, no solo un medio de subsistencia, sino la posibilidad de fundar un nuevo lugar de enunciación y de adquirir cierta legitimidad intelectual insubordinada a los aparatos exclusivos, tradicionales, de la república de las letras (Ramos, 2009: 172).

En el primer número de $R M$, del $1^{\circ}$. de julio de 1898 , José Juan Tablada ofrece una fábula titulada "Exempligratia o Fábula de los siete trovadores y la Revista Moderna", en la que se relata la historia de siete trovadores que se encuentran, en su periplo, con hostilidad, vulgaridad e indiferencia. En todos los casos, la mala acogida cobra su cuota y los hostiles e indiferentes reciben maldiciones o son consumidos por el fuego. Los trovadores permanecen, al final, como estatuas de nieve que provocan admiración y piedad al que se topa con ellos. Con esta fábula, "sus iniciadores
4. Derivado de la publicación en El País, en 1893, del poema de José Juan Tablada, "Misa negra”, que causó indignación general por herir el pudor y la moral de los lectores, entre los que se encontraba Carmen Romero Rubio, la esposa del entonces presidente de la República, Porfirio Díaz. Para mayores detalles a propósito de este escándalo, véase, entre otros, a Valdés, 1987: xvii-xviii. 
marcan alegóricamente su distancia del público común, haciéndose encarnar en siete trovadores provenzales que se detienen a cantar ante un grupo de cortesanos embrutecidos por el vino y los placeres: 'el gruñido de los puercos de Circe era lo único que contestaba al canto alado de los trovadores"' (Ruiz Castañeda, 1988: s.p.). Tras el relato, Tablada remata con un texto que, los especialistas han señalado una y otra vez, funciona lo mismo como advertencia, bienvenida y prospecto: “ $~ ¡ O h$, público de la Revista Moderna!, obra a tu guisa, y si sólo tu indiferencia hemos de merecer, seguiremos con gusto la suerte de aquellos nuestros precursores, los siete troveros medioevales..." (se refiere, desde luego, a los miembros de la primera redacción: Couto, Urueta, Tablada, Dávalos, Campos, Ceballos y Olaguíbel o Valenzuela [s.p.]). Más adelante, en el primer número que conocemos de $R M$-digo esto por la teoría de un primer número perdido y algunas evidencias que la acreditan - se ofrece una suerte de definición formal de la Revista, en la sección "Notas de actualidad", resabio de la prensa periódica de la que procede:

Relatar sucesos y acaso deslizar juicios rápidos entre ellos es lo que procuraremos realizar en la Revista Moderna, que no lleva al publicarse otro objeto que el de ofrecer su modesto contingente al progreso intelectual del país, ajena como ella lo será a toda pasión política; fácil empresa, por cierto, para personas como los redactores de este periódico, todos ellos sin ligas interesadas ni compadrazgos de elogios mutuos; ni menos todavía, fatuidades y ambiciones ridículas (Veritas, 1898: 15).

El tono de las escasas notas políticas no se aleja, como no lo hace prácticamente ninguna pieza publicada en $R M$, del tono inmodesto, enfático, que la caracterizará al fin. La confusión/asimilación con el periódico y con el libro, en los primeros números de $R M$, con los que discrepa en ritmo de publicación, temática y propósitos, tiene un sentido incluyente a propósito de los lectores que contradice el texto de Tablada. La doble bienvenida se sostiene en ambas bifurcaciones en diversos sitios de la revista durante toda su vida. A ellas respondería el aserto de Adela Pineda Franco a propósito del supuesto elitismo literario frente al público que, a pesar suyo, "participó en la (re) producción de sujetos ciudadanos pertinentes a la cultura del orden y el progreso, a partir del incremento en la demanda lectora que la modernización de la prensa y del Estado había acarreado" (Pineda Franco, 2006: 155).

La efímera sección dedicada a la política me interesa porque, en su deriva, ilustra el desarrollo de $R M$ de impreso "misceláneo" corriente (revue) a "pequeña revista" (petite revue), por su negativa a derivar en un impreso informativo dedicado al gros public y su afán de especialización: la mayor parte de su contenido está dedicada a la promoción de expresiones artísticas de una escuela estética muy específica (Vérilhac, 2001: 362-363). Como objeto mediático, la petite revue, aparece hacia el final del siglo XIX y, principios del XX, en Europa (particularmente en Francia), y personifica un momento de redefinición del campo literario y artístico al encarnar un modo original e inédito de hacer literatura (Vérilhac, 2011:359). Acudo al término petite revue propuesto por Yoan Vérilhac para describir el fenómeno porque, me parece, me ayuda a explicar el formato y la circulación de $R M$ - con las salvedades del caso, desde luego-: se trata de una pequeña empresa mediática financieramente inestable - dependiente, como dije antes, en el mejor de los casos, de una suerte de mecenas-, situación que explica la elección de su formato (pequeña revista), equipo de redacción reducido, periodicidad inestable (quincenal, mensual o bimensual), paginación variable y el espíritu artesanal que le confiere valores simbólicos como rareza, delicadeza y belleza: la puesta en página de la poesía (como género dominante) y de las ilustraciones es definitoria de su naturaleza. Su equipo certifica solidaridades estéticas, amistosas y es un "prolongement de la façon particulière dont se vit la vie littéraire à la fin du siècle, et un vecteur puissant de la joie de faire de la littérature une aventure collective" (Vérilhac, 2011: 359-363). 
Las primeras petites revues ofrecieron títulos que las identificaban como órganos consagrados a una escuela estética y a un grupo devoto a ella ubicado en los márgenes del sistema. La idea de especialización de este objeto respondía, entonces, menos a una restricción a propósito de temas o campos de interés que a un punto de vista y una enunciación que los afectaba: su discurso está sostenido por un "nosotros" que encierra una colectividad, reivindicada y asumida, que reúne lo mismo a redactores que a lectores (Vérilhac, 2011: 363-364).

\section{Antes de "nosotros"}

En un breve examen por la prensa del período en busca de rastros de recepción en el interés a propósito del nacimiento de $R M$ (cuyo primer número conocido es del $1^{\circ}$. de julio de 1898), no he encontrado más que tres menciones. ${ }^{5}$ Me refiero a una publicada en La Patria, ${ }^{6}$ diario liberal que saluda al periódico en términos elogiosos:

En los cristales elegantes de Plateros ha aparecido por estos días un anuncio extraño: algo no producido por los artífices de la orfebrería ni por los dedos de hada que hacen flores de seda: se anuncia una Revista Moderna en la que lidiarán por el arte soberbias plumas diamantinas.

La constelación de nombres ya gloriosos de Couto, Ceballos, Dávalos, Leduc, Tablada, Urueta, Valenzuela, irradia como un septuor de pléyades en el cielo del arte, en las modernas letras de América, en la florescencia latina del verbo sublimado, hecho perla por el beso misterioso de luz de genio que ha fecundado esos potentes cerebros creadores.

Ruelas, el artista de la línea, el que da la vida en un rasgo perfilado, el trabajador escondido que surgirá un día no lejano, eclipsando glorias efímeras con su pincel, será director artístico de esa Revista Moderna.

¡Bienvenida la sibila preconizadora de la moderna encarnación del Dios-Arte, luz y amor, juventud y fuerza, libertad y poderío, radiación de haces solares cuya claridad cegará y sublevará, pero iluminará! (Oro, 1898: 1).

La bienvenida proviene, y esto hay que decirlo, de un miembro de la capilla que la Revista identifica y legitima (Rubén M. Campos). La otra referencia es de parte de Tablada, y configura una suerte de remate a la polémica surgida en 1898: "Quiero ser el heraldo de esa buena nueva, y os diré que el estadio desierto y desolado se animará lleno de triunfantes fanfarrias [...] El olmo secular de la justicia, el trono forestal. Es un periódico exclusivamente literario [...] El periódico de que os hablo aparecerá en breve. Se intitulará $R M$, y creo que no os es necesario saber más..." (Clark de Lara y Zavala, 2002: 315-316). Otras menciones halladas son meramente comerciales, pero no dejan de ser significativas: la $R M$ se solía anunciar en el periódico católico $E l$ Tiempo, 7 al lado de El Gato Negro. Semanario Ilustrado, por ser ambas producto de la casa editorial Ramón de S. N. Araluce, Sucr. de Párres. El aviso comercial se refiere a los dos impresos en los mismos términos, como fundidos identitariamente en uno solo: "El interés palpitante de ambas revistas por el relato de los sucesos más importantes de actualidad, sus numerosas y bien acabadas ilustraciones dotadas de un texto encomendado a plumas importantes, hacen de las mismas, en nuestro concepto, que sean las más notables del día en su género" (Revista Moderna, 28 de julio de 1898: 3). Si bien se entiende que se trata más de una estrategia comercial que de un gesto de comprensión de estos impresos como servicio para los posibles lectores, es sugerente que se subrayen tres elementos que otorgaban valor y atractivo a los objetos impresos en ese momento: las noticias de actualidad, las ilustraciones y, debajo de ellas, o
5. Otras referencias a $R M$, ya en circulación, aparecieron incluso en la prensa extranjera. Pineda Franco alude a ellas en detalle: "Al lado de esta configuración del lector modelo como cofrade de los productores decadentistas, la revista proporciona evidencias de su recepción histórica al publicar cartas y reseñas provenientes de otras publicaciones: un balance de El Mercurio de América de Buenos Aires (15 de diciembre de 1898: 158), una polémica entablada con La Estrella Occidental (159-60), una reseña crítica de El Combate, enero de 1899: 32) y un artículo de El Cojo llustrado sobre revistas mexicanas (octubre de 1905: 77-78). En todos estos casos, se trata de una recepción literaria" (2006a: 156).

6. La Patria (1877-1914), periódico "político, científico, literario, comercial y de anuncios", dirigido por Ireneo Paz (1877-1908), era un diario que se autoproclamaba justo, imparcial e independiente, de tendencia liberal. Durante un tiempo, afín al régimen de Porfirio Díaz, aunque, más tarde reveló un talante más crítico, lo que le costó a Paz, el encarcelamiento por un breve tiempo (Paz, 1997: 5).

7. El Tiempo (1883-1912), diario dirigido por Victoriano Agüeros que se autoproclamaba mexicano en política y católico-apostólico-romano en religión. En el prospecto, Agüeros declaraba que a su impreso le incumbía "hacer prevalecer las enseñanzas de la Iglesia en el Estado, en la sociedad, en la familia, y aún en el individuo" (Agüeros, 1883: 1). 
dependiendo de éstas, mejor dicho, las buenas plumas. $R M$ en muchos sentidos quiere cumplir, en sus primeros números, con ello, aunque el equilibrio de estos factores terminará por contravenir lo declarado en el aviso.

Mientras el "nosotros" se configura y se estabiliza, la revista avanza en sentido contrario al anuncio. Otra cosa será cuando llegue a su segunda época, en que por cuestiones de mercado se vea forzada a mudar a magazine mensual y a hacer justicia a su publicidad inicial. Un dato más de lectura en el que me interesa detenerme: José López Portillo escribe un artículo dedicado a Julio Ruelas, para el número 4 de febrero de 1902 de $R M$, que inicia afirmando una práctica probablemente usual: "Lo primero que hago al recibir las entregas de Revista Moderna es hojear el cuaderno en busca de las ilustraciones de Ruelas, y detenerme con interés a examinar cada una de ellas [...] Hay entre la Revista Moderna y su dibujante una consonancia pasmosa" (Revista Moderna, 1987: t. 5, 54-55). Portillo y Rojas no hace más que señalar algo que terminó por ser determinante para la fisonomía del objeto y para la práctica lectora que esto configuró (Revista Moderna, 1987: t. 1, xxv): el peso específico de las ilustraciones de Ruelas en $R M$ estimuló el particular diálogo que se establecía con los textos, además de reiterar una decidida idea de renovación estética como divisa de la revista: una modernidad muy propia y excéntrica.

Es un hecho que El Tiempo dedicó alguna vez sus columnas a criticar a los redactores de $R M$. Encuentro una alusión a ello en La Patria, una réplica a una crítica injuriosa hecha a los colaboradores de $R M$ en El Tiempo; en esta nota se apunta a la "ignorancia de los lectores" del diario católico, de cuyo nivel intelectual tienen triste idea, aunque admiten que su director, Agüeros, se precia -y quizás sea esta la razón que explique el anuncio inserto en sus columnas, además de precio y redes de amistad, desde luego-de "coadyuvar a la popularización de la literatura" (S.A., 1898:1). Es claro que el perfil de los lectores de este diario era más afín a los censores que a los modernistas, por lo que resulta chocante la reproducción de este anuncio en el impreso católico, por lo menos durante 1898, mientras El Gato Negro, revista originaria de Barcelona e ilustrada a colores, circuló en México.

La aparente falta de interés en $R M$ es, en todo caso, engañosa y legitimadora, como veremos adelante. Los modernistas estaban en la palestra y las polémicas les confirieron, lo admiten la mayor parte de los especialistas, un capital simbólico que más tarde cederían a su órgano de difusión: el "nosotros" estaba en construcción. En la polémica de 1893 - que derivó en el surgimiento de $R M$ y que tuvo gran repercusiónsurgió, muy temprano, una de las pocas menciones a propósito del nacimiento del impreso. Ante la publicación de unos versos de Balbino Dávalos, "Preludio", dedicados a la revista - anteriores a los de Tablada-, se afirmó que habían sido leídos "una noche antes en una reunión íntima, celebrada con el objetivo de acordar la próxima edición de la "Revista Moderna [...] 'nos complacemos en prender en nuestras columnas esa flor, una de las primeras que han brotado en el Invernadero Decadentista" (Zavala, 2018: 98). Y es justamente al inicio de 1898 , año de nacimiento de $R M$, que la polémica contra los modernistas se reaviva, tras una carta enviada por Victoriano Salado Álvarez a Francisco M. de Olaguíbel en la que, con el pretexto de hablar de Oro ynegro, critica con dureza a la escuela modernista (de naturaleza decadente) por "desviarse del buen camino". ${ }^{8}$ Entre réplica y réplica, esta polémica, que Nervo prefirió calificar como "grato departimiento", (Clark de Lara y Zavala, 2002: 295), no dejó de ser agria y se prolongó hasta el mes de marzo de 1898.

En un panorama más propicio que el de 1893 , la $R M$ empieza a circular en el mes de julio. Una vez fuera, ciertamente recibirá atención, con pequeñas notas que anuncien bien las conferencias o veladas que solían organizar en las oficinas de su redacción o en Chapultepec, bien por las críticas al Modernismo que se hicieron costumbre,
897 en El Mundo. Para seguir ésta otras polémicas modernistas, consúltese Clark de Lara y Zavala 2002 
bien por la preocupación respecto de su salud financiera y la posibilidad de su deceso. Estas menciones, me refiero a las últimas, surgen bien pronto y la acompañan durante toda su vida:9 en octubre de 1898 , La Patria, por ejemplo, publica una nota en la que revela que el director de $R M$ ha hecho circular una hoja en la que hace una "excitativa al patriotismo de los amantes de las letras para que contribuyan al sostenimiento de la citada revista".

The Mexican Herald, en una breve nota sin título ni autor aparecida el 12 de febrero de 1901 , insiste en aplicar a $R M$, a la que le reconoce un valor aparentemente no visible para todos en esa coyuntura, el argumento del desdén como prerrogativa de los modernistas: "The Revista Moderna is a local fortnightly paper devoted to the higher literature [...] but the public prefere something of a lower grade. However, some future historian of Mexico will note appreciatively the work which is being done by the poets and prose writers who produce the Revista Moderna" (4). Veremos abajo cómo este "nosotros", que se ha ido configurando en las polémicas y empieza a tomar cuerpo en $R M$ en las prácticas lectoras que quiere impulsar, funciona insertado en un espacio representacional como Alejandro Mejías López sostiene a propósito del "nosotros" de José Martí-con un doble alcance: "la apelación a una unidad interna y a una modernidad posible con la que enfrentar otras modernidades posibles" (Mejías López, 2006: 151). Este proceso lo llevará, paradójicamente, en una doble dirección: exclusión e inclusión; oposición y consentimiento, cerrazón y apertura, que terminará por asimilarla a las otras modernidades posibles para sobrevivir; lo mismo sucederá a su "nosotros", que acabará siendo muy amplio y borroso.

\section{La endogamia del "nosotros"}

El "nosotros", que incluye y excluye, pero que, sobre todo, legitima el proyecto, empieza a aparecer muy pronto, y las apologías que a partir del número uno publica Ciro B. Ceballos son claramente funcionales a este respecto; en la primera, dedicada a Balbino Dávalos, sostiene:

[...] labores tan quintaesenciadas como la de Balbino Dávalos, solo son aquilatadas aquí, en su mérito intrínseco, por un selecto y reducidísimo número de amigos o admiradores[...] Verdad es que a él le bastan los lectores de Barbey d'Aurevilly y nada le chocaría tanto como ser popular entre la gentecilla cursi o ver sus producciones revueltas con las gavillas de lugares comunes que se sirven al lector burgués en las secciones literarias de los días de fiesta (Ceballos, 1898a: 10).

Antes, Ceballos ha dicho que la obra breve de Dávalos contradice a los lectores trogloditas, de canina voracidad, que tragan obras como las de Montepin. En la segunda apología, relativa a Rafael Delgado, Ceballos se refiere a los lectores de la prensa amarilla y a su experiencia lectora como a "porcina gula de nuestras purulencias sociales" (Ceballos, 1898b: 5); en lo que se constituye como evidente declaración de principios, no tanto a propósito de los lectores como de la autonomización del campo literario, que la existencia de la revista quiere posibilitar. Esta voluntad autonómica se reitera, además, en el posicionamiento temático de la propia revista (literaria y científica), que evidencia un primer elemento central en las lógicas de organización del campo de la producción intelectual en ese momento, con la aparición de revistas cada vez más especializadas: científicas, religiosas, jurídicas, literarias [...] (Loué, 2011: 352-353).

Ceballos no era ajeno a los excesos encomiosos de su pluma. En la apología dedicada a Urueta, llega a afirmar un aserto aparentemente público: "Se ha repetido con insistencia que aquí se elogia incondicionalmente a propios y extraños" (Ceballos, 1899:
9. Pienso en el apartado que Julio Sesto dedica al RM y en el que, todavía en 1910, para su segunda época, se lamenta por la probable muerte del impreso. Sesto insistirá en que el peor enemigo de la prensa mexicana del período será el “indiferentismo de la raza: no se lee en proporción de los habitantes" (1910: 35), argumento que, por cierto, invalidaría la singularidad de $R M$ respecto a sus lectores, al igualarla con los impresos periódicos de la época. 
10. La nota merece ser reproducida en su integridad: "Como pudiera ocurrir que alguno interpretase perversamente, la aparición en este periódico, del artículo arriba publicado, hago saber que se ha entregado a las cajas a petición de mis compañeros y con la desaprobación del elogiado, a quien ha desobedecido esta vez la redacción, por considerar, de acuerdo común, que el caso no afecta ni relaja en lo más mínimo la disciplina de ella" (Ceballos, 1898c: 105).

11. Sabine Schlickers explica esta extraña criatura: “La novela posmodernista-naturalista superó esta posición ambivalente y crítica de los modernistas frente a la modernidad, ejerciendo de nuevo una función estabilizadora de sus dos esferas" (2003: 382).
40). Y agrega: “¿Acaso han visto los motejadores a través de nuestros elogios el morboso anhelo de verlos correspondidos con rédito usurario en alguna hoja redactada por esos preciosos ridículos que tienen el parencéfalo repleto de la materia que integra la palabra de Cambrone?" (Ceballos, 1899: 40). Ceballos entiende que le conviene justificar la validez de esta práctica, y lo hace cada tanto, como en la apología a Jesús E. Valenzuela, a la que añade una nota en la que explica su publicación a pesar del rechazo del elogiado. ${ }^{10}$ La función legitimadora de estos textos (Pineda Franco, 2005: 226) y la "redefinición del quehacer literario como crítica de la modernidad a partir de la difícil relación" entre el público lector y los escritores - como otra vez señala Pineda Franco (Pineda Franco, 2011: 130) - ayudan a vislumbrar al lector ideal de $R M$, pero también al empírico, al abonado regular.

En otro trabajo (Rodríguez González, 2012) sostuve que un dicho de Nervo a propósito de sus posibles lectores encontraba sustento, precisamente, en el primer número de $R M$. Nervo afirmaba que en México "se escribe para los que escriben" y que el literato cuenta con un cenáculo de escogidos que lo leen y hace de ellos su único público: "El gros public, como dicen los franceses, ni lo paga ni lo comprende, por sencillo que sea lo que escribe; ¿qué cosa más natural que escriba para los que si no lo pagan lo comprenden al menos?" (Nervo, 1896: 164). Sostengo, pues, que el diálogo intertextual que sostuvieron Ciro B. Ceballos y José Ferrel en dos textos en forma de carta, publicados en el número inicial de $R M$, reiteran la convicción nerviana: la pieza de Ferrel se publica en $R M$ como una suerte de contestación a otro texto, publicado fuera de $R M$, pero que se inserta en ella gracias a esta propuesta de diálogo/reseña. Ambos representan, como expliqué, un complejo artificio literario, similar en funciones a las apologías, que tuvieron en Ceballos a uno de sus mayores representantes, y que abonaron a favor de la autosuficiencia, necesaria, a decir de Héctor Valdés, para estabilizar la situación de la revista en sus inicios y afirmar las cualidades de sus colaboradores (Valdés, 1987: 62).

La respuesta literaria de Ferrel, titulada "La consulta de Pedro", en la forma de un cuento-epístola, forma parte del proceso de estabilización y afirmación del grupo modernista y se constituye en un mecanismo de propaganda ciertamente moderno. No abundaré en el análisis en esta ocasión, porque ya lo hice en otro texto sobre el tema, pero sí insistiré en una idea que me ayuda a configurar al lector-modelo y al lector-empírico de $R M$ que vislumbro en estos textos. Lo que me parece fascinante de "La consulta de Pedro" es que sea, a un tiempo, la puesta en escena de un tipo de escritura "modernista" y de su lectura: la que se hacía desde la ciencia, desde la razón, desde esa posición modernista de filiación naturalista que cumplía con una función estabilizadora. ${ }^{11}$

De este modo, la lucha que se establece entre instinto y razón en estos textos no hace más que alimentar las contradicciones que sustentan al Modernismo, de filiación decadente, y que nos hacen ir de la fascinación al disgusto, es decir, que nos obligan a hacer una doble lectura que va de la celebración al diagnóstico, de lo tentador a lo amenazante (Molloy, 1992: 21). ¿No es esto, me pregunto, una señal de complacencia obligada hacia los lectores y no el desdén anunciado en las polémicas y en la propia revista? Me parece que sí. Con Julio Ramos pienso que se trata del fenómeno de modernización desigual, esto es, el resultado de un intento de autonomización, o bien de precisión del campo de autoridad social, enfrentado a la imposibilidad de su institucionalización (Molloy, 2009: 55): la falta de lectores, por constituir estos un grupo reducido, es favorable y congruente con el proyecto, pero perjudicial para su salud financiera.

Esto sucede asimismo con la doble enunciación del perfil de lector que procura $R M$. Si tras un breve análisis del contenido podemos afirmar que la heterogeneidad de 
contenido y de convivencia en $R M$ es la regla, qué decir respecto de sus lectores. Y no se trata, como algunos pueden afirmar, de una contradicción, sino de una propiedad de origen, identitaria. Así, entre Darío, Poe, Valenzuela y Schwob aparece Federico Gamboa, y en un número en que predomina Gabino Barreda y la reforma educativa, se suma un relato de Rafael Delgado. La singularidad de $R M$, como sostuve antes al filiarla con la petite revue, no está cifrada tanto en la variedad de su contenido como en su "evasiva a definiciones precisas" (Pineda Franco, 2015: t. 1, parr. 1), lo mismo que su antecesora, la Revista Azul. Un rasgo, por cierto, reconocido muy pronto por los miembros de la redacción y traducido por Jesús Valenzuela en "una santa comunión del arte", donde conviven Couto, Othón, Tablada y Delgado: "Toda la cuestión estriba -insiste Valenzuela- en trabajar armónicamente en la dirección del ideal", para "dejar libre en el espacio adquirido, o no adquirido todavía, a la joven mariposa del pensamiento" (Clark de Lara y Curiel, 2000: 36-37); una suerte de camaradería imposible, pero conveniente en todo caso.

Este atributo, sumado a una indefinición del término "modernismo", complica el trazo de su recepción. En diversos sitios en $R M$, esta indeterminación es reiterada constantemente: basta con hojear los primeros números para comprobarlo. Por ejemplo, en una sección que en algunas entregas se titula "Pensamientos diversos" y en otras aparece sin identificar, se ofrece una idea de Alfonse Daudet en la que se sostiene que "No hay escuelas o, mejor dicho, no debe haberlas; no hay más que obras, buenas o malas", mientras que en otro momento, una idea de Stendhal parece justificar/legitimar apologías y autoencomios: "De colega a colega, los elogios son certificados de semejanza" (1898, año 1, núm. 3: 36). Si bien es verdad que la aparición o ausencia de esta sección, digamos, variable, en cada entrega responde, fundamentalmente, a temas de formato - pues aparece para llenar blancos en números para los que no hay piezas que puedan rendir ese servicio-, lo cierto es que no se puede negar que la elección de los textos que conforman la sección es deliberada o, por lo menos, que no es ingenua ni ajena a la legitimación del objeto. Desechar tales textos por el mero argumento de su funcionalidad material es ignorar los indicios de lectura que ofrece, justamente, ese rasgo material. Otro ejemplo de indeterminación: Ceballos, quien en su empeño por legitimar la práctica de la apología y trazar, al mismo tiempo, el paradigma del lector ideal, utiliza la figura de uno de los miembros de $R M$ para, desde su negativo, sostener el modelo: “¿Se nos ha visto padecer las megalomanías de Amado Nervo, ese sonámbulo del Modernismo, que cuando tañe su enervada lira creyendo estremecer las siete ciudades que disputaban a Homero, solo logra que aborten las cursis lectoras de sus versos hiperestesiados?" (1899: 40). En fin, los lectores no encuentran en este impreso un trabajo de edición que simplifique, abrevie, ilustre o recorte los textos que $R M$ le ofrece para su reconocimiento: lo que hallan es la posibilidad de descubrir estas piezas en su singularidad, en los vínculos estéticos que le sugieren (Chartier, 2005: 32-33); esto ubica a sus lectores, a pesar de toda indeterminación, por el momento, lejos del gros public.

Si hacia el final del siglo XIX, como afirma Julio Ramos, el estatuto de "escritor moderno" es problemático (Ramos, 2009: 58), el de "lector moderno" no puede ser menos complejo. La revolución que sufrió la lectura hacia el final del siglo XIX, con una oferta desigual y demandante, derivada de los avances industriales llevados a la prensa, más los nuevos formatos, temáticas, ritmos y retóricas que esta le impuso a la sociedad, produce lectores que también cumplen con roles múltiples: lo mismo leen la prensa metropolitana que los restos de la tradicional; un semanario ilustrado que una revista moderna; un impreso misceláneo que otro especializado. ¿Cómo gestionan las apropiaciones de estos textos los lectores, en términos de especialización? Poco se discute a propósito de lo que sucede con el lector durante el proceso - trunco o no- de autonomización del discurso: la posibilidad de generar lectores instruidos, sofisticados, debería ir de la mano con la de institucionalización del campo. 
En esta modernización desigual que le toca enfrentar a $R M$, la endogamia lectora -con gesto de exclusión-y el eclecticismo -en discreta, pero clara apertura - son, me parece, las primeras soluciones al impedimento que parece imponer el "nosotros" que la amparó en un inicio. No resulta extraño, entonces, que $R M$, nacida de un impulso polémico y disidente, ya mesurada, evite hablar de modernismo y decadentismo y empiece a ser más amplia y menos estable. Si bien no hay escuelas (ha quedado zanjada ya la discusión a propósito del decadentismo), sí hay afinidades y un diseño inicial que configuró prácticas y lectores, y a ellos apela $R M$ para negociar con lsa otras prácticas, los otros lectores y las otras modernidades, y poder optar por un eclecticismo que necesita ser conciliador para que la revista sobreviva. 


\section{Bibliografía}

" Agüeros, V. (1883). “Editorial. ‘El Tiempo'”. En El Tiempo, jueves 24 de mayo de 1883, año 1, Prospecto, p. 1.

»Campo, Á. de (1991 [1939]). “De la novela nacional”. En Pueblo y canto, pról. y sel. de Mauricio Magdaleno. México: Universidad Nacional Autónoma de México, pp. 124-128.

"Ceballos, C. B. (1898a). “Seis apologías. Balbino Dávalos”. En Revista Moderna. Literaria y Artística, 1‥ de julio de 1898, año 1, núm. 1, p. 10.

»Ceballos, C. B. (1898b). “Seis apologías. Rafael Delgado". En Revista Moderna. Literaria y Artística, 18 de agosto de 1898, año 1, núm. 2, p. 5.

»Ceballos, C. B. (1898c). “Nota” a “Seis apologías. Jesús E. Valenzuela”. En Revista Moderna, 1 de noviembre de 1898, año 1, núm. 7, p. 105.

»Ceballos, C. B. (1899). “Seis apologías. Jesús Urueta”. En Revista Moderna, febrero de 1899, año 2, núm. 2, p. 40.

»Chartier, R., El orden de los libros. Lectores, autores, bibliotecas en Europa entre los siglos XIV y XVIII. Pról. de

»Ricardo García Cárcel. Barcelona: Gedisa.

»Clark de Lara, B.y Zavala. A. L. (2002). La construcción del modernismo. (Antología). México: Universidad Nacional Autónoma de México.

"Clark de Lara, B., Zavala. A. L. y Curiel Defossé, F. (2000). El modernismo en México a través de cinco revistas. México: Universidad Nacional Autónoma de México.

" Goldgel, V. (2013). Cuando lo nuevo conquistó América. Prensa, moda y literatura en el siglo XIX. Buenos Aires: Siglo Veintiuno Editores.

»Loué, T. (2011). “La revue”. En Dominique Kalifa, Philippe Régnier, Marie-Éve Thérenty y Alain Valillant (dirs.), La civilisation du journal. Histoire culturelle et littéraire de la presse française au XIXe siècle. París: Nouveau Monde, pp. 333-357.

" Mejías López, A. (2006). “'Conocer y ser conocido’: identidad cultural, mercado y discursos globales en tres revistas latinoamericanas de entre siglos". En Revista Iberoamericana, enero-marzo de 2006, vol. 72, núm. 214, pp. 139-153.

»Molloy, S. (1992). "Lecturas de descubrimiento: la otra cara del fin de siglo". En Juan Villegas (ed.), Actas Irvine-92. Asociación Internacional de Hispanistas, t. 1: De historia, lingüística, retóricas y poéticas. Irvine: Universidad de California, pp.17-28.

"Nervo, A. (Rip-Rip) (1896). "Fuegos fatuos. Los poetas mexicanos y el pueblo". En El Nacional, 27 de junio de 1896, núm. 297, p. 2, citado por Clark de Lara y Zavala, 2002: 187-191.

»Oro [Rubén M. Campos] (1898). “Causerie”. En La Patria, 19 de junio de 1898, p. 1.

»Pacheco, J. E. (1999). Antología del modernismo (1884-1921). México: Era-Universidad Nacional Autónoma de México.

" Paz, O. (1997). "Silueta de Ireneo Paz". En Vuelta, febrero de 1997, núm. 243, pp. 4-8. 
»Pineda Franco, A. (2005). “El cosmopolitismo de la Revista Moderna (1898-1911): una vocación porfiriana”. En Belem Clark de Lara y Elisa Speckman Guerra (eds.), La República de las letras. Asomos a la cultura escrita del México decimonónico. T. 2: Publicaciones periódicas y otros impresos. México: Universidad Nacional Autónoma de México, pp. 223-238.

»Pineda Franco, A. (2006a). "Más allá del interior modernista: el rostro porfiriano de la Revista Moderna (1903-1911)". En Revista Iberoamericana, enero-marzo de 2006, vol. 72, núm. 214, pp. 155-169.

»Pineda Franco, A. (2006b). "Del interior modernista al foro público: la Revista Moderna en sus dos épocas". En Geopolíticas de la cultura finisecular en Buenos Aires, París y México: las revistas literarias y el modernismo. Pittsburgh: Instituto Internacional de Literatura Iberoamericana, pp. 105-128.

»Pineda Franco, A. (2011). “La modernidad de Ángel de Campo, Micrós”. En Miguel Ángel Castro (ed.), Pueblo y canto. La ciudad de Ángel de Campo, Micrós y Tick-Tack. Homenaje en el centenario de su muerte. México: Universidad Nacional Autónoma de México, pp. 127-137.

»Pineda Franco, A. (2015). “El afrancesamiento modernista de la Revista Azul (18941896): ¿Un arte decadente o una apología del progreso positivista?”. En Javier Pérez Siller (dir.), México-Francia, memoria de una sensibilidad común, siglos XIX-XX. México: Centro de Estudios Mexicanos y Centroamericanos-El Colegio de San Luis A.C.-Benemérita Universidad Autónoma de Puebla, pp. 395-417. En línea: <http://books.openedition.org/cemca/4082?lang=es > (consulta: 10-12-2019).

" Ramos, J. (2009). Desencuentros de la modernidad en América Latina. Literatura y política en el siglo XIX. Caracas: Fundación Editorial El Perro y la Rana.

»Revista Moderna (1987). Revista Moderna. Arte y Ciencia. Edición facsimilar. Noticia de Fernando Curiel; prólogo de Julio Torri; estudio introductorio de Héctor Valdés. México: Universidad Nacional Autónoma de México, 1987, 5 ts.

»Rodríguez González, Y. (2012). “La recepción endogámica entre los decadentes mexicanos: Ciro B. Ceballos, José Ferrel y El caso de Pedro". En Stefano Tedeschi y Sergio Botta (eds.), Rumbos del hispanismo en el umbral del cincuentenario de la Asociación Internacional de Hispanistas, t. 6: Hispanoamérica. Roma: Bagatto Libri, 2012, pp. 436-443.

» Ruiz Castañeda, M. C. (1988). “Revista Moderna”. En Nexos, 1 de mayo de 1988, s.p. En línea: <https://www.nexos.com.mx/?p=5122> (consulta: 10-12-2019).

» S.A. (1898). “La Revista Moderna y El Tiempo". En La Patria de México. Diario, jueves 18 de agosto de 1898 .

» Schlickers, Sabine (2003). El lado oscuro de la modernización. Estudios sobre la novela naturalista hispanoamericana. Frankfurt/M.-Madrid: Vervuert-Iberoamericana.

» Sesto, J. (1910). El México de Porfirio Díaz. (Hombres y cosas). Estudios sobre el desenvolvimiento general de la República mexicana. Observaciones hechas en el terreno oficial y en el particular. Valencia: F. Semper y Compañía, 1910.

» Speckman, E. (2005). “Las posibles lecturas de La República de las letras. Escritores, visiones y lectores". En Belem Clark de Lara y Elisa Speckman Guerra (eds.), La República de las letras. Asomos a la cultura escrita del México decimonónico. T. 1: Ambientes, asociaciones y grupos. Movimientos, temas y género literarios. México: Universidad Nacional Autónoma de México, pp. 47-74.

» Tablada, J. (1893). “Carta”. En El País, 15 de enero de 1893, p. 2, citada en Valdés, 1987: xxi. 
»Valdés, Héctor (1987). "Estudio introductorio" a Revista Moderna. Ed. facs. México: Universidad Nacional Autónoma de México, pp. xv-xxxviii.

» Vérilhac, Y. (2011). “La petite revue”. En Dominique Kalifa, Philippe Régnier, Marie-Éve Thérenty y Alain

"Valillant (dirs.), La civilisation du journal. Histoire culturelle et littéraire de la presse française au XIXe siècle. París: Nouveau Monde, pp. 359-373.

»Veritas (1898). “Notas de actualidad”. En Revista Moderna. Literaria y Artística, 1 de julio de 1898, año 1, núm. 1, p. 15.

»Zavala, A. L. (1998). “Hacia la construcción de una comunidad emocional letrada: polémicas modernistas-decadentistas en el México porfiriano". En Entre Caníbales. Revista de Literatura, año 2, junio de 2018, núm. 8, pp. 93-110. 
